\title{
RELATIONSHIPS BETWEEN PERSONALITY, EMOTIONAL LABOR, WORK ENGAGEMENT AND JOB SATISFACTION IN SERVICE PROFESSIONS
}

\author{
JUSTYNA MRÓZ and KINGA KALETA \\ Jan Kochanowski University in Kielce, Kielce, Poland \\ Institute of Pedagogy and Psychology, Faculty of Pedagogy and Art
}

\begin{abstract}
Objectives: Although there have been studies linking personality to selected aspects of functioning at work, Polish literature reports a shortage of detailed analyses considering, e.g., specific professional groups or certain variables. The aim of our study was to explore the links between personality traits and emotional labor, work engagement and job satisfaction among service workers. Material and Methods: The study was based on a cross-sectional, self-report survey of 137 workers representing different service industries in Poland. Each participant received a demographic data sheet and a set of questionnaires: NEO Five-Factor Inventory, the Deep Acting and Surface Acting Scale, the Job Satisfaction Scale and the Utrecht Work Engagement Scale - all in their Polish versions. Results: A correlation analysis revealed numerous relationships between the examined variables. However, results of the regression analysis showed that only some personality traits were related with individual aspects of functioning at work. Neuroticism accounted for the phenomenon of faking emotions. Conscientiousness was significantly related to general work engagement, vigor and dedication. Agreeableness and neuroticism significantly predicted job satisfaction. Conclusions: Individual personality traits account for various aspects of work functioning. Int J Occup Med Environ Health 2016;29(5):767-782
\end{abstract}

Key words:

Personality, Job satisfaction, Big five, Work engagement, Emotional labor, Service profession

\section{INTRODUCTION}

The roots and outcomes of functioning at work have been addressed by a number of studies. While looking for variables accounting for an individual's successful functioning at work, researchers have referred to factors related to job characteristics and to an employee's personality traits. One of the frequently considered variables is personality defined as a constant pattern of traits, tendencies or characteristics that make an individual's behavior stable [1]. Costa and McCrae [2,3] have presented a famous model of personality known as the Five-Factor Model, often referred to as the big five. The model includes such features as neuroticism, extraversion, openness to experience, agreeableness and conscientiousness. Neurotic individuals are characterized as vulnerable and inclined to experience negative emotions. Extraverted people are energetic, assertive, active and sociable, and they tend to experience positive emotions. Openness to experience is defined by such qualities as open-mindedness, divergent thinking and artistic creativity. Agreeableness implies such traits as warmth, trust and cooperativeness. Finally, conscientiousness, which describes individuals who are well-organized,

Received: January 20, 2015. Accepted: October 5, 2015.

Corresponding author: J. Mróz, Jan Kochanowski University in Kielce, Institute of Pedagogy and Psychology, Faculty of Pedagogy and Art, Krakowska 11, 25-029 Kielce, Poland (e-mail: justyna_mroz@wp.pl). 
responsible, reliable, thorough and hardworking [3-5]. Using these personality traits, researchers have explained various aspects of work functioning, e.g., job performance [6], organizational behavior [7] or workaholism [8]. A large variety of existing professions includes those in the case of which successful performance depends specifically on an individual's interpersonal predispositions. This relates, for instance, to social service professions, which involve working directly with people and thus, particularly frequent and close contacts with clients. Apart from professional competencies, such professions require more emotional engagement in interactions with clients than other jobs [9].

Therefore, an important aspect of functioning at work is emotional labor, which can have either positive or negative consequences for an employee. What is interesting though, is that contemporary studies concerning functioning in service occupations have excessively focused on negative outcomes, such as stress [10] or burnout [11]. As a result of taking efficient actions with regard to those issues, researchers tend to turn their attention to work engagement [12] and job satisfaction. They describe those aspects of direct interactions with people which are in demand. Emotional labor, work engagement and job satisfaction are correlated with job-describing variables [1315], but also with non-work relations [16] and a worker's personality [17-20]. The purpose of the present study was to analyze the relationships between personality traits distinguished in the Five-Factor Model and emotional labor, work engagement and satisfaction derived from the work in services.

Another argument which should be taken into consideration, is the fact that studies focusing on the above variables, and especially on emotional labor, have been rarely conducted in cultural zones outside the United States [21,22], whereas cross-national research has shown interesting differences between Western and Eastern service workers. For instance, display rules related to anger, fear and sadness experienced at work are more restrictive in Singapore when compared to the United States, although display rules for happiness, disgust and contempt are equivalent across these 2 nations [23].

Moreover, studies conducted by Klassen, Uher, and Bong [24] have shown differences in job satisfaction among teachers in North America (USA, Canada) and Korea. Teachers in Korea were less satisfied with their job than those in America. Additionally, job satisfaction was associated with job stress only among North American teachers. Results of the study by Hu et al. [25] have also revealed differences in the levels of work engagement across employees of Eastern and Western cultures. Employees in countries such as the Netherlands, Spain, and Finland show higher levels of work engagement than employees in China and Japan. These findings suggest that Polish population may also differ from other nations as it incorporates elements of both Western and Eastern culture [26,27].

\section{Emotional labor}

Emotional labor is a specific aspect of functioning in an occupation involving service, which is likely to be correlated with personality traits. The term "emotional labor," introduced by Hochschild [28], refers to expressing emotions expected to be shown during professional interactions in occupations involving providing services. Emotional labor is an indispensable component of a professional role and it is continually performed during doing professional duties. It requires control of one's emotions, so as to, during interactions with clients (patients, students, guests), display emotional states that meet the demands determined by an employer and job characteristics. Its purpose is to evoke specific emotions in clients, most often positive ones, and consequently, to achieve objectives set out by an organization or company.

In this context, emotion control increases effectiveness and constitutes an element of the performed profession, for which a worker is remunerated. It also increases 
self-efficacy, facilitates an employee's self-expression and strengthens his/her identification with the role. This, in turn, may make emotional labor enjoyable and improve mental and physical well-being [29,30]. Emotional labor is demanding, therefore, it also results in stress, burnout, lower job satisfaction or deteriorating health [30-35]. Hochschild [28] has pointed out that emotional labor may involve surface or deep acting. Surface acting involves changing one's emotional expression when dealing with clients, but only by putting on an appearance and presenting signs of the required emotions, such as benevolence, enthusiasm or interest. Meanwhile, the employee's personal emotions remain unchanged. Therefore, despite putting on a happy face, he or she may in fact feel reluctant. In deep acting, on the other hand, personal impressions change and this leads to modification of an emotional expression. In practice, emotional labor means suppression, hiding, faking or strengthening emotions or their expression; however, according to Ashforth and Humphrey [30], the term also refers to expressing true emotions that comply with the standards determined for a given profession. Emotional labor, perceived as internal emotion regulation processes [31,36,37], depending on its form, requires activation of different strategies. Deep acting requires antecedents, i.e., actions at the beginning of the emotional process, before an emotion and its expression are fully experienced. These actions include selection or modification of circumstances, focused attention and cognitive reinterpretation - the way of thinking about a given situation that will increase or reduce the chances for the emotion to emerge [36].

On the other hand, surface acting involves modification of the emotional response, when no antecedents have been applied or they have proved unsuccessful. Lee and Brotheridge [37] have distinguished 2 components of surface acting: hiding and faking emotions. Faking emotions means pretending the feelings which are expected from an employee and expressing unfelt emotions, while hiding feelings - suppressing negative or adverse emotions, restraining expression of the true feelings or concealing one's emotions.

According to Grandey [36], surface acting involves higher costs and leads to less favorable outcomes than deep acting. Many studies $[18,31,34,38-44]$ confirm this hypothesis. At the same time, research findings have shown a positive correlation between deep acting and the feeling of personal accomplishment [31,32,34]. However, there are some differences between countries regarding emotional labor, e.g., a study comparing American and Chinese service workers [45] has shown that surface acting was less likely to contribute to job burnout among the Chinese. The findings have also shown a negative correlation between deep acting and depersonalization among the Chinese workers, but no such effect was identified in the case of the American employees. In other words, service workers in these 2 cultures, individualistic and collectivistic, experience different consequences of emotional labor. This observation may be of importance in our study, as it was conducted in a culture characterized by a mixture of the values from the 2 mentioned above countries.

Previous studies investigating emotional labor have shown that its type and intensity also depend on various aspects of a service provider's personality [34,46-49]. Personality most often has been analyzed according to the big five model, which made it possible to identify varied relationships between personality traits and emotional labor.

And so, neuroticism correlated with surface acting, and agreeableness and extraversion with deep acting [41,50,51]. Conscientiousness negatively correlated with surface acting [50] and positively with deep acting [52], and also extraversion negatively predicted surface acting [53]. A study conducted in a group of teachers has shown that openness to experience correlated positively with surface acting and deep acting [52]. Findings of a survey conducted among people employed in Korean tourism industry has shown that extraversion and conscientiousness had a positive 
influence on deep acting; and agreeableness and openness had a positive impact on both surface and deep acting [54]. Based on the above studies, we predicted that neuroticism would positively correlate with surface acting, extraversion, and openness; conscientiousness would correlate positively with deep acting and negatively with surface acting, whereas agreeableness would show a positive relationship with both surface and deep acting (H1). This hypothesis may be supported by the following potential mechanisms [3-5].

Neurotic people are nervous, stressed, unsatisfied and tend to experience a variety of negative emotions, including anxiety, guilt, sadness and angry hostility. Their emotional labor, i.e., showing emotions relevant for the performed profession, may, therefore, be a form of defense against an anticipated unfavorable response of the environment to their authentic negative emotions. For this reason, such individuals may suppress their real feelings and express fake emotions expected of them by the clients. Extraverted people, having qualities such as warmth, cheerfulness and vigor, feel more comfortable in professional interactions requiring a smile, or an expression of enthusiasm or interest. Therefore, they may engage in deep acting rather than in surface acting.

Similarly, individuals open to experience, who perceive interpersonal cues and are generally interested in interactions with other people, may naturally engage in deep acting. Still, because of their nonconformity, they may be reluctant to perform surface acting, which requires adjustment to imposed rules and creates artificial interactions. On the other hand, conscientiousness, which implies ethical consistency, may foster deep acting as a behavior which is true to one's personality and it may mitigate the tendency to hide and fake feelings, as a form of manipulation. However, for individuals with a high level of agreeableness, appropriate relations and cooperation with others are so important that they may engage in both forms of emotional labor.

\section{Work engagement}

The work engagement model predominantly used in research has been proposed by Schaufeli et al. [55]. Work engagement is defined as “(...) a positive, fulfilling, workrelated state of mind that is characterized by vigor, dedication, and absorption" [55, p. 74]. Vigor refers to the high amount of energy and flexibility displayed by an individual at work. It is also manifested by the persistence and effort put into work despite any encountered difficulties. Dedication is related to the sense of pride, meaning and purpose as well as inspiration and enthusiasm; and it makes occupational events being perceived like a challenge. Absorption, on the other hand, is related to being completely focused on the job. An individual is so preoccupied with his/her work that he/she cannot take a break, and time is running very fast [55]. Available studies have reported a higher level of work engagement among employees from the Western countries when compared to the Eastern cultures [25,56]. The relationship between personality and work engagement has been confirmed in numerous studies, yet the findings are inconsistent. Available results suggest that conscientiousness is correlated with work engagement, not only in general but also in the aspects of vigor, dedication and absorption [57-60]. This correlation is positive. What is more, neuroticism is generally negatively correlated with work engagement [58-60] or vigor [57].

Although essentially related to social involvement, extraversion is reported to correlate with work engagement in diverse ways. A study by Woods and Sofat [61] in British adults employed in office environments, suggests a positive correlation between extraversion and engagement, yet this finding has not been confirmed by the study investigating employees of the freight department of an airport in China [58]. On the other hand, the correlation between agreeableness and work engagement was either positive [58-60] or statistically non-significant.

A high level of openness to experience points to experiential engagement, however, in this case, just like in the case 
of extraversion, associations are diverse - either positive [60] or there are no relationships [57]. Work engagement is an ongoing process rather than an isolated event. Therefore, it requires triggering resources by an individual. By using their resources, such as ability to work systematically, to plan, meet deadlines and obey rules, employees are able to engage in tasks they were entrusted with, and derive satisfaction from them. Hence, these tasks are not perceived as excessively demanding, but rather as a prospect of development [58].

By reference to the available studies and theoretical framework regarding work engagement and the big five model, we put forward a hypothesis that personality traits related to work engagement include conscientiousness (positive correlation), extraversion (positive correlation), agreeableness (positive correlation) and neuroticism (negative) (H2).

\section{Job satisfaction}

Another measure describing functioning at work is satisfaction derived from the performed professional role. Job satisfaction is the most popular term, emphasizing a subjective nature of such an evaluation. Job satisfaction is defined as giving meaning and quality to professional duties [62]. While describing satisfaction derived from performance of a professional role, attention is paid to its emotional and cognitive aspect. Emotional aspect involves feelings towards work and feelings generated at work [62]. Cognitive aspect, on the other hand, refers to what individuals think about and how they evaluate their work [62]. The cognitive aspect may be related either to individual evaluations (remuneration, working conditions, opportunities for development) or to the overall evaluation [63].

Correlation between personality and job satisfaction has been confirmed by research findings [17,64]. However, correlations between the traits distinguished in the big five model and job satisfaction vary. Judge et al. [64] carried out a meta-analysis, which has shown that extraversion and conscientiousness (both positively correlated) as well as neuroticism (negatively correlated) were the most significant traits for professional satisfaction. This finding has been confirmed, for example, by a study focusing on a group of sworn police officers. That study has shown a negative correlation of job satisfaction with neuroticism, and a positive correlation with extraversion and conscientiousness [17].

While analyzing the relationship between individual personality traits and job satisfaction, attention should be paid to certain mechanisms. Individuals with high levels of neuroticism experience a greater number of negative events than others, even at work. On the other hand, extraverted individuals establish more professional relationships that can foster greater professional satisfaction, especially in service professions. Conscientiousness is conducive to greater professional efficiency, which increases the likelihood of obtaining satisfying benefits from work, both formal (pay, promotion) and informal (recognition) [64].

With the aforesaid findings in mind and based on the big five model, we put forward a hypothesis that extraversion and conscientiousness would be positively correlated, while neuroticism would be negatively correlated with job satisfaction (H3).

Summing up, the purpose of the present study was to analyze the relationships between personality traits and work engagement, emotional labor (surface and deep acting), and job satisfaction among individuals performing professions involving providing services.

\section{MATERIAL AND METHODS \\ Participants}

The sample was strictly selected and consisted of 137 participants performing service professions from the Southern Poland area (Kielce). Their selection was determined by the nature of the analyzed variables, especially of emotional labor which these occupations involve. Women 
accounted for $90.5 \%(\mathrm{~N}=124)$ of the group and men for the remaining $9.5 \%(\mathrm{~N}=13)$.

The subjects' age ranged 20-54 years with the mean (M) of 37.18 (standard deviation $(\mathrm{SD})=10.19$ ), whereas their work experience ranged $1-33$ years $(\mathrm{M}=18.12$, $\mathrm{SD}=7.41$ ). All the study participants were economically active and they were employed in service industries (41\% in commercial and 59\% in non-commercial sectors). Professions they performed included, e.g., a nurse, a waitress, a receptionist, a seller, a guide, a coach, an account advisor. The sample included both commercial and noncommercial service providers because this approach made it possible to acquire results concerning service professions in general.

Approximately $50 \%$ of the participants had secondary education, $21.3 \%$ - college education, whereas $27.9 \%$ of them had higher education. The participants most often described their financial situation as average $(46.7 \%)$ or good (41.6\%). Sixty-four percent of the respondents were married, $2.9 \%$ of them were widowed, $5.9 \%$ divorced, whereas the remaining $26.5 \%$ were single.

\section{Measures}

The following questionnaires were employed in the study:

- Personality - traits were measured using the Polish version of the NEO Five-Factor Inventory by Costa and McCrae [65]. The inventory measures 5 basic personality traits included in the big five theory [2], i.e., neuroticism, extraversion, openness to experience, agreeableness, conscientiousness. The inventory consists of 60 items, 12 items per 5 scales. Respondents are asked to indicate to what extent they agree with each item using a 5-point scale (1 - strongly disagree, 5 - strongly agree). Cronbach's $\alpha$ for the subscales ranged from 0.68 to 0.82 .

- Emotional labor - was assessed by the use of The Deep Acting and Surface Acting Scale (DASAS) by Finogenow et al. [66], which is an adaptation of the revised scale developed by Brotheridge and Lee [37,67]. It is a 9-item self-report measure, describing 3 different types of emotional labor (3 items per each subscale): deep acting, hiding feelings, faking emotions. The items are scored on a 5-point scale from "never" to "always." In the Polish version Cronbach's $\alpha$ for the subscales ranged from 0.72 to 0.82 .

- Job satisfaction. Assessment of job satisfaction was carried out by means of the Satisfaction with Job Scale developed by Zalewska [62]. It is a 5-item scale measuring a general, subjective level of job satisfaction in terms of the cognitive aspect. Each item is rated on a 7-point scale (1 - "I completely disagree," 7 - "I absolutely agree"). The internal consistency of the scale is satisfactory (Cronbach's $\alpha$ ranged from 0.81 to 0.88 ).

- Work engagement - was measured with the Utrecht Work Engagement Scale $[55,68]$. The UWES is a 17item scale (a full version) and the items are scored on a 7-point scale (0 - never, 6 - everyday). During the adaptation process, Chirkowska-Smolak [68] tested a 1-factor and a 3-factor solution. Both models had a good fit. Therefore, the UWES may be treated as a 3-factor and a 1-factor scale in terms of the total score. In the present study, the full version was used. The scale describes 3 aspects of engagement: vigor, dedication, absorption. The scale reliability was also confirmed, Cronbach's $\alpha$ ranged from 0.77 to 0.92 .

\section{RESULTS}

Descriptive statistics and the correlation coefficients between the analyzed variables are presented in Table 1. Correlation analysis revealed positive and negative relationships between personality traits and work-related variables. In terms of emotional labor, neuroticism turned out to be positively related to faking emotions, and extraversion was negatively related to hiding feelings. As regards work engagement, neuroticism correlated negatively with vigor; and extraversion was positively correlated with vigor, absorption 


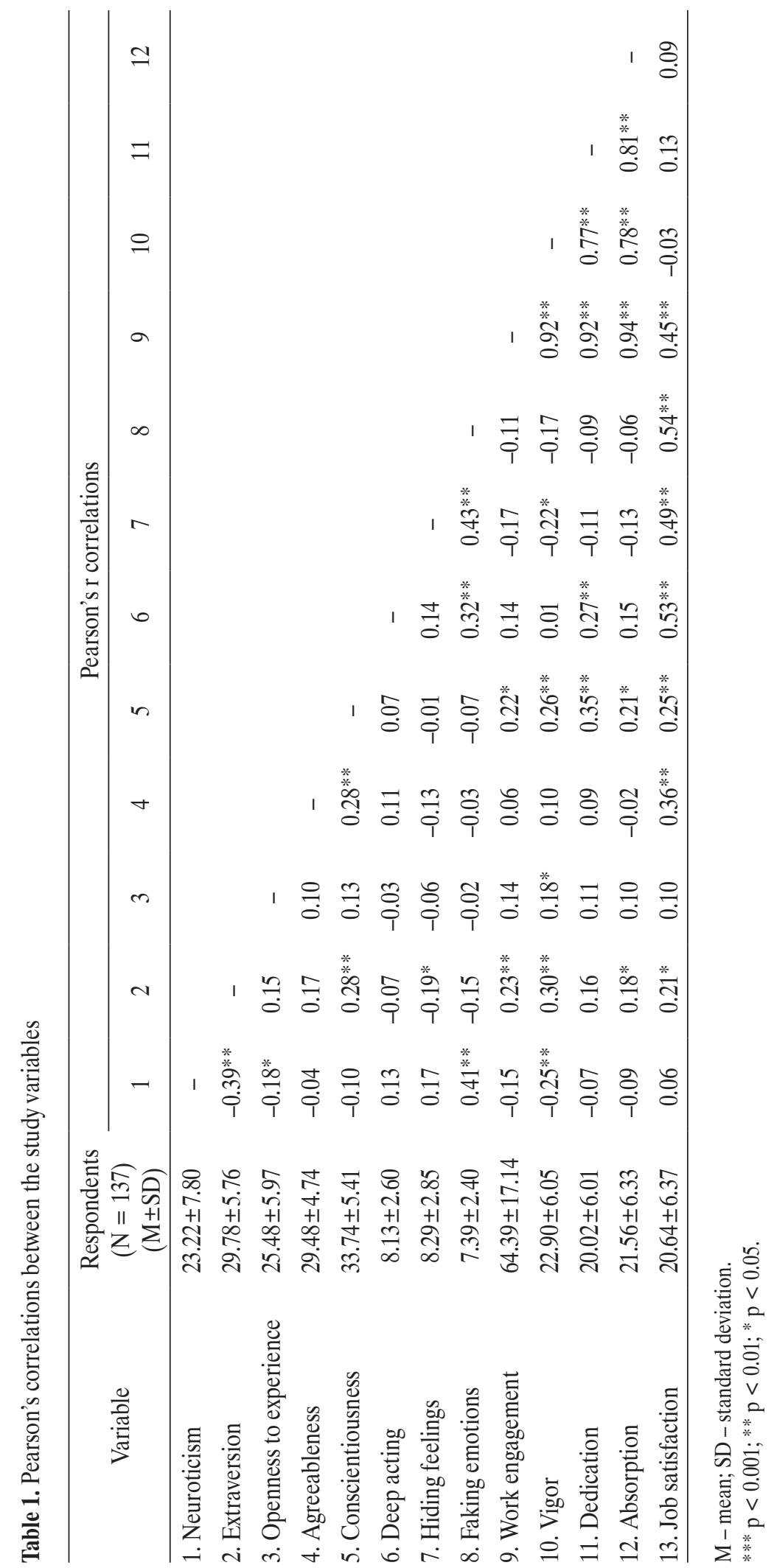


and general engagement. Openness to experience was positively associated with vigor, whereas conscientiousness was positively correlated with all the aspects of work engagement. Finally, higher extraversion, agreeableness and conscientiousness were related to greater job satisfaction.

Subsequently, a series of regression analyses were performed. Table 2 shows the results of the multiple regression analysis conducted to reveal whether personality significantly predicts emotional labor (deep acting, faking emotions, hiding feelings). Neuroticism, as the only trait, significantly predicted faking emotions $(\beta=0.13$, $\mathrm{p}<0.001,95 \%$ confidence interval $(\mathrm{CI}): 0.07-0.18)$. This variable explained $17 \%$ of variance in faking emotions $(\mathrm{F}(5,123)=4.748, \mathrm{p}<0.001)$.

As shown in Table 3, all the 5 traits of personality (extraversion, neuroticism, openness to experience, agreeableness and conscientiousness) accounted for $8-15 \%$ of the variance in work engagement, vigor, dedication and absorption. One personality factor, i.e., conscientiousness, was significantly related to work engagement $(\beta=0.56, \mathrm{p}<0.002,95 \% \mathrm{CI}$ : $0.21-0.92)$, vigor $(\beta=0.13, \mathrm{p}<0.021,95 \%$ CI: $0.02-0.24)$ and dedication $(\beta=0.32, \mathrm{p}<0.001,95 \% \mathrm{CI}$ : $0.16-0.48)$. In the case of absorption, the $\mathrm{F}$ values indicated that personality traits had no significant effect.

Table 2. Regression results predicting emotional labor

\begin{tabular}{lrcccccccc}
\hline \multirow{2}{*}{\multicolumn{1}{c}{ Variable }} & \multicolumn{3}{c}{ Deep acting $^{\mathrm{a}}$} & \multicolumn{3}{c}{ Hiding feelings $^{\mathrm{b}}$} & \multicolumn{3}{c}{ Faking emotions $^{\mathrm{c}}$} \\
\cline { 2 - 10 } & $\beta$ & $\mathrm{SE}$ & $\mathrm{p}$ & $\beta$ & $\mathrm{SE}$ & $\mathrm{p}$ & $\beta$ & $\mathrm{SE}$ & $\mathrm{p}$ \\
\hline Neuroticism & 0.04 & 0.03 & 0.219 & 0.04 & 0.04 & 0.288 & 0.13 & 0.03 & 0.000 \\
Extraversion & -0.03 & 0.04 & 0.556 & -0.08 & 0.05 & 0.120 & 0.01 & 0.04 & 0.789 \\
Openness to experience & -0.00 & 0.04 & 0.840 & -0.01 & 0.04 & 0.883 & 0.02 & 0.03 & 0.540 \\
Agreeableness & 0.06 & 0.05 & 0.251 & -0.07 & 0.05 & 0.221 & -0.01 & 0.04 & 0.779 \\
Conscientiousness & 0.04 & 0.04 & 0.401 & 0.04 & 0.05 & 0.471 & -0.01 & 0.04 & 0.764 \\
\hline
\end{tabular}

${ }^{\mathrm{a}} \mathrm{R}=0.19, \mathrm{R}^{2}=0.038, \mathrm{~F}(5,123)=0.962, \mathrm{p}<0.444$.

${ }^{\mathrm{b}} \mathrm{R}=0.24, \mathrm{R}^{2}=0.06, \mathrm{~F}(5,123)=1.60, \mathrm{p}<0.161$.

${ }^{\mathrm{c}} \mathrm{R}=0.41, \mathrm{R}^{2}=0.17, \mathrm{~F}(5,123)=4.748, \mathrm{p}<0.001$

$\mathrm{R}$ - the coefficient of determination; $\mathrm{R}^{2}$ - the percent of the dependent variable explained by the model; $\mathrm{F}$ - the value of statistic test; $\beta$ - standardized coefficient; SE - standard error.

Table 3. Regression results predicting work engagement, vigor, dedication, absorption

\begin{tabular}{lccccccccccccc}
\hline \multirow{2}{*}{ Variable } & \multicolumn{3}{c}{ Work engagement $^{\mathrm{a}}$} & \multicolumn{4}{c}{ Vigor $^{\mathrm{b}}$} & \multicolumn{4}{c}{ Dedication $^{\mathrm{c}}$} & \multicolumn{4}{c}{ Absorption $^{\mathrm{d}}$} \\
\cline { 2 - 14 } & \multicolumn{1}{c}{$\beta$} & $\mathrm{SE}$ & $\mathrm{p}$ & $\beta$ & $\mathrm{SE}$ & $\mathrm{p}$ & $\beta$ & $\mathrm{SE}$ & $\mathrm{p}$ & $\beta$ & $\mathrm{SE}$ & $\mathrm{p}$ \\
\hline Neuroticism & -0.04 & 0.13 & 0.769 & -0.06 & 0.04 & 0.146 & 0.01 & 0.06 & 0.867 & 0.01 & 0.04 & 0.816 \\
Extraversion & 0.27 & 0.18 & 0.134 & 0.10 & 0.05 & 0.063 & 0.07 & 0.08 & 0.358 & 0.09 & 0.06 & 0.132 \\
Openness to experience & 0.16 & 0.15 & 0.318 & 0.05 & 0.05 & 0.322 & 0.05 & 0.07 & 0.480 & 0.06 & 0.05 & 0.268 \\
Agreeableness & -0.08 & 0.20 & 0.683 & -0.02 & 0.06 & 0.739 & -0.01 & 0.09 & 0.909 & -0.05 & 0.07 & 0.450 \\
Conscientiousness & 0.56 & 0.18 & 0.002 & 0.13 & 0.05 & 0.021 & 0.32 & 0.08 & 0.000 & 0.12 & 0.06 & 0.054 \\
\hline
\end{tabular}

${ }^{\mathrm{a}} \mathrm{R}=0.37, \mathrm{R}^{2}=0.14, \mathrm{~F}(5,123)=3.96, \mathrm{p}<0.002$.

${ }^{\mathrm{b}} \mathrm{R}=0.39, \mathrm{R}^{2}=0.15, \mathrm{~F}(5,123)=4.42, \mathrm{p}<0.001$.

${ }^{\mathrm{c}} \mathrm{R}=0.38, \mathrm{R}^{2}=0.15, \mathrm{~F}(5,123)=4.27, \mathrm{p}<0.001$.

${ }^{\mathrm{d}} \mathrm{R}=0.28, \mathrm{R}^{2}=0.08, \mathrm{~F}(5,123)=2.07, \mathrm{p}<0.07$.

Abbreviations as in Table 2. 
Table 4. Regression results predicting job satisfaction

\begin{tabular}{lccc}
\hline \multirow{2}{*}{ Variable } & \multicolumn{3}{c}{ Job satisfaction $^{\mathrm{a}}$} \\
\cline { 2 - 4 } & $\beta$ & $\mathrm{SE}$ & $\mathrm{p}$ \\
\hline Neuroticism & 0.15 & 0.07 & 0.049 \\
Extraversion & 0.20 & 0.10 & 0.054 \\
Openness to experience & 0.05 & 0.09 & 0.577 \\
Agreeableness & 0.37 & 0.12 & 0.002 \\
Conscientiousness & 0.20 & 0.10 & 0.055 \\
\hline
\end{tabular}

${ }^{a} \mathrm{R}=0.43, \mathrm{R}^{2}=0.19, \mathrm{~F}(5,125)=5.77, \mathrm{p}<0.001$.

Abbreviations as in Table 2.

Next, the relationship between personality traits and job satisfaction was assessed (see Table 4). The analysis showed that the factors significant for job satisfaction were: neuroticism ( $\beta=0.15, \mathrm{p}<0.049,95 \% \mathrm{CI}$ : $0-0.3$ ) and agreeableness $(\beta=0.37, \mathrm{p}<0.001,95 \% \mathrm{CI}: 0.14$ $0.6)$. These variables explained $19 \%$ of job satisfaction $(\mathrm{F}(5,125)=5.77, \mathrm{p}<0.001)$. On the other hand, conscientiousness and extraversion were related to job satisfaction indicating a trend (95\% CI: 0-0.41).

\section{DISCUSSION}

The purpose of the study was to analyze the relationship between personality traits distinguished in the big five model and emotional labor, work engagement and job satisfaction in individuals performing jobs requiring direct contact with a client/patient. Furthermore, an attempt was made to determine to what extent personality traits account for aspects of functioning at work adopted in the study.

First, the hypothesis that we put forward, i.e., that there is a relationship between personality and emotional labor was partly supported. Only neuroticism and extraversion correlated with emotional labor, whereas the findings of regression analysis supported only high significance of neuroticism in the tendency to express fake feelings. Other authors have also reported a positive correlation between neuroticism and surface acting [41,50-52]. Faking emotions, which is one of the main components of surface acting, may be interpreted as an attempt to win favorable approach of the environment.

According to Gore and Pincus [69], neuroticism is correlated with destructive overdependence. As neurotic individuals feel unable to care for themselves, uncomfortable or helpless when alone and they experience lack of self-confidence, they seek relationships as a source of care or support. Emotional labor may be one of the forms of a submissive behavior motivated by loneliness and fear of losing approval [69]. However, the mere act of hiding feelings may be perceived by neurotic persons as insufficient to gain and maintain people's friendliness, therefore, they feel the pressure to evoke a smile, kindness and enthusiasm. As predicted, the findings also showed a negative correlation between extraversion and hiding feelings. At the same time, none of the examined personality traits proved to be significantly correlated with deep acting, which is contrary to the authors' expectations and earlier studies.

Indeed, it has been previously demonstrated that individuals who were more extraverted, agreeable [50,51], open and conscientious [52] tended to engage more frequently in deep acting. One explanation accentuates assertiveness, responsibility and reliability of those individuals. They may be focused more on their professional duties than on emotions regulation. This tendency may also result from 
the specificity of the Polish population. Polish culture is described as rather individualistic and at the same time highly restrained [27]. In such societies employees rely on formal rules, appreciate tasks more than relationships, are less likely to experience positive affect and prefer honest sharing of feelings. Therefore, they are reserved in professional interactions and less likely to express positive emotions, which, in fact, they do not feel. For Polish service workers, emotional labor actually might not be a form of self-expression.

Generally, the weak correlations between personality traits and emotional labor identified by the study gain additional meaning if we analyze the consequences of emotions regulation for professional purposes. As proposed by Grandey et al. [70], emotional labor, especially surface acting, leads to the loss of resources as it consumes attention and energy, weakens the feeling of bond, and consequently leads to stress and burnout. This has been confirmed, in particular, by previous Polish studies $[34,35]$. Surprisingly these were not only both forms of surface acting, but also deep acting that positively correlated with emotional exhaustion and depersonalization. Moreover, no form of emotional labor was positively associated with personal accomplishment.

These results, not consistent with the theory and other studies $[29,30,32,34]$, may again point to a specificity of Polish population. When compared to the employees from other cultural areas (USA and China), Polish service workers, due to their individualistic and restrained attitude, experience more negative and fewer positive consequences of emotional labor [45]. This, in turn, possibly leads to burnout. Given the above, the only positive correlation between neuroticism and surface acting (faking) confirmed in the study is favorable in the sense that specific personality traits do not themselves determine either the tendency to engage in emotional labor or the risk of burnout in service jobs.

Most probably, the use of emotional labor is determined by an interaction of various personality- and work-related factors, such as working conditions, salaries, achievement and promotion opportunities, atmosphere, well-being in the workplace, etc. These aspects may compensate emotional costs.

Moreover, in our study surface and deep acting were positively correlated with job satisfaction. Employees who assessed their job positively were more likely to perform emotional labor. Satisfaction with working conditions is probably a stronger incentive to engage in surface and deep acting than personality traits.

The second hypothesis was partly supported by the evidence showing that conscientiousness was the most effective predictor of work engagement. It is consistent with the finding that conscientiousness was perceived as a personality-based predictor of job performance and motivation to work [70]. These results confirmed the assumptions that in societies with high uncertainty avoidance, Poland being a good example, precision and formalization are conducive to work engagement. Moreover, such societies strongly believe in the importance of obeying rules and regulations. For this reason, employees who willingly obey rules are able to engage in tasks they were entrusted with, and draw satisfaction from their fulfillment [27].

Other personality traits showed single significant correlations (extraversion, neuroticism, openness) with work engagement. While making an attempt to explain our results, it may be observed that professional contact with a client/ patient requires adjustment to another person at various levels, as well as flexibility in expressing emotions [28]. Therefore, an average level of neuroticism appears to be beneficial for work engagement. It may enable higher flexibility in responding to a client/patient's needs, and the employee may also appear to be more approachable, as suggested by a client/patient's experience. Moreover, no correlation between agreeableness and engagement may account for the results of the study by Poraj [71], as well as by Tabała et al. [72], in which a negative correlation has 
been found between agreeableness and emotional burnout as well as depersonalization, and no such relationship has been identified in the case of job performance. It may be concluded that agreeableness has protective significance for negative signs of the lack of involvement, whereas it has no significance for positive work engagement [71,72]. On the other hand, the unexpected correlation between vigor and openness to experience may suggest that employees focusing on looking for new experiences will more readily engage in professional duties, treating them not as an obligation but as an opportunity to grow and encounter someone or something new. This has been also confirmed by the study conducted among teachers of public sector universities in Pakistan [59].

The authors found the results related to the correlations between personality traits and job satisfaction quite surprising (H3). Results of the regression analysis showed that agreeableness and neuroticism (positive correlation) played a statistically significant role in accounting for job satisfaction, which had not been assumed in the hypotheses.

Previous studies have reported positive correlations or no associations between agreeableness and job satisfaction [64]. However, no findings have been reported on a positive correlation between neuroticism and job satisfaction. Agreeableness is an important trait in professions involving significant interpersonal interaction; even more so, if the job involves providing assistance or care for others [73]. Therefore, employees displaying warmth, evoking confidence, showing kindness and cooperation are likely to experience signs of appreciation from their clients/ patients. This, in turn, would be conducive to their satisfaction derived from their professional activity. A positive correlation between neuroticism and job satisfaction in the regression equation proved rather surprising. This result was contrary to the findings which have reported emotional stability to be one of the major personality predictors related to work efficiency [73].
Highly neurotic individuals display a greater need for engaging in relations with others [61], this need also being fostered by increased agreeableness. This tendency may prove positively significant for evaluating one's work in a service profession as satisfactory by females living in male cultures. Polish culture is classified as approximating the masculine pole in the masculinity-femininity continuum [27]. Extraversion and conscientiousness correlated only with job satisfaction. Direct interactions with another person, just like responsibility, reliability, precision and diligence, are conducive to job performance [74], which, on the other hand, translates to job satisfaction. Therefore, it may be concluded that some personality traits may fulfill a mediating or moderating role between working conditions and job satisfaction.

\section{CONCLUSIONS}

In summary, the study broadens knowledge about correlations between personality and selected aspects of functioning at work. Our results lead to a conclusion that only some personality traits relate significantly to emotional labor, work engagement and job satisfaction among service providers. Neuroticism, conscientiousness and agreeableness proved to be the most significant ones. Neuroticism accounted for faking emotions, conscientiousness predicted vigor, dedication and general engagement at work; whereas agreeableness and neuroticism were significantly correlated with job satisfaction.

The present study also suggests practical conclusions. What needs to be emphasized is that, being rather individualist and restrained, Polish service workers treat their job as a natural expression of their personality only to a minor extent. From the executive point of view, these are clear guidelines for those in managing positions. As in our culture surface and deep acting are difficult and costly to perform, to enhance an employee's involvement in emotional labor, the use of financial and non-material incentives is indispensable. 
All satisfying aspects of working conditions can make up for intrapersonal costs and reinforce motivation for work. What is more, service workers should be trained in most effective emotional labor strategies. Improving social skills and reducing emotional costs would be beneficial not only for the employers, but also for the employees themselves. Secondly, the results could be applied in professional counseling and career planning. Person-environment fit, taking personality into account, can promote job satisfaction [75] and protect against burnout [76]. This is important as service workers are especially prone to job burnout.

Finally, it is necessary to mention limitations of the study. First of all, the sample was relatively small, which means that the findings describe trends rather than facts. It would be advisable to retest the outcomes using a different sample. Also, the sample was overrepresented by the female respondents who differ from men, e.g., in the level of neuroticism [65]. Controlling gender of respondents in future studies may be helpful in explaining some unexpected relationships between the variables.

Another issue is the sampling method, and the fact that the sample was composed of the individuals representing professions from various service sectors, including commercial and non-commercial ones. This may be important because studies concerning emotional labor conducted among workers performing different jobs [34] and in homogenous groups [35] have provided inconsistent results. Future studies should pay more attention to the variable of a profession. Additionally, specificity of the performed work may be significantly different, e.g., it may generate diverse stress levels [10], which may consequently be related to the examined variables. Also, working conditions such as working time, workplace, or satisfaction with a salary were not examined. For instance, a study devoted to nurses indicated that workload, unsatisfactory pay and promotion conditions, low prestige of the profession, and job uncertainty were the sources of burnout and low morale [77]. Those variables may be the mediating or moderating factors for the examined correlations. Moreover, all the variables were assessed by the use of selfreport methods, which provide information that may be imprecise because of their declarative nature.

Indeed, some authors have suggested [49] that in order to present themselves in a better light, people may refrain from admitting that they fake emotions. Further research should take this into consideration by controlling for a social desirability variable. Another issue is the cross-sectional character of the study. Due to changes in all the aspects of functioning at work, a longitudinal study would be more advisable. Finally, it should be noted that validation of the tool used to measure emotional labor is still pending.

\section{REFERENCES}

1. Arshadi N, Danesh F. Designing and testing a model of precedents and outcomes of emotional labour in an industrial organization in Iran. Procedia Soc Behav Sci. 2013;84:1529-33, http://dx.doi.org/10.1016/j.sbspro.2013.06.784.

2. Costa PT, McCrae RR. Revised NEO Personality Inventory (NEO-PI-R) and NEO Five-Factor Inventory (NEO-FFI). Professional manual. Odessa (FL): Psychological Assessment Resources; 1992.

3. Costa PT, McCrae RR. Domains and facets: Hierarchical personality assessment using the Revised NEO Personality Inventory. J Pers Assess. 1995;64(1):21-50, http://dx.doi. org/10.1207/s15327752jpa6401_2.

4. Costa PT, McCrae RR. Influence of extraversion and neuroticism on subjective well-being: Happy and unhappy people. J Pers Soc Psychol. 1980;38(4):668-78, http://dx.doi. org/10.1037/0022-3514.38.4.668.

5. McCrae RR, Costa PT. Adding Liebe und Arbeit: The full Five-Factor Model of well-being. Pers Soc Psychol Bull. 1991; 17(2):227-32, http://dx.doi.org/10.1177/014616729101700217.

6. Bhatti MA, Battour MM, Ismail AR, Sundram VP. Effects of personality traits (big five) on expatriates adjustment and job performance. Equality Divers Inclusion. 2014;33(1):73-96, http://dx.doi.org/10.1108/EDI-01-2013-0001. 
7. Chiaburu DS, Oh IS, Berry CM, Li N, Gardner RG. The five-factor model of personality traits and organizational citizenship behaviors: A meta-analysis. J Appl Psychol. 2011;96(6):1140-66, http://dx.doi.org/10.1037/a0024004.

8. Andreassen AS, Hetland J, Pallesen J. The relationship between 'workaholism', basic needs satisfaction at work and personality. Eur J Pers. 2010;24:3-17, http://dx.doi. org/10.1002/per.737.

9. Bajcar B, Borkowska A, Czerw A, Gąsiorowska A. [Job satisfaction in jobs with social mission. Psychological determinants]. Gdańsk: Gdańskie Wydawnictwo Psychologiczne; 2011. Polish.

10. Ogińska-Bulik N. [Occupational stress in social service jobs. Sources - Consequences - Prevention]. Warszawa: Difin; 2006. Polish.

11. Bakker AB, van der Zee KI, Lewig KA, Dollard MF. The relationship between the Big Five personality factors and burnout: A study among volunteer counselors. J Soc Psychol. 2006;146(1):31-50, http://dx.doi.org/10.3200/SOCP.146.1.31-50.

12. Schaufeli WB. Work engagement. What do we know and where do we go? Rom J Appl Psychol. 2012;14(1):3-10.

13. Morris JA, Feldman DC. The dimensions, antecedent, and consequences of emotional labor. Acad Manage Rev. 1996;21(4): 986-1010, http://dx.doi.org/10.5465/AMR.1996.9704071861.

14. Freeney YM, Tiernan J. Exploration of the facilitators of and barriers to work engagement in nursing. Int J Nurs Stud. 2009;46:1557-65, http://dx.doi.org/10.1016/ j.jinurstu.2009.05.003.

15. Hofmans J, de Gieter S, Pepermans R. Individual differences in the relationship between satisfaction with job rewards and job satisfaction. J Vocat Behav. 2013;82:1-9, http:// dx.doi.org/10.1016/j.jvb.2012.06.007.

16. Mróz J, Kaleta K. [Family relationships and psychological aspects of work functioning]. In: Margasiński A, editor. [Family in the systems - Centered perspective. Theory and research]. Warszawa: Polskie Towarzystwo Psychologiczne; 2015. p. 52-77. Polish.

17. Miller AH, Mire S, Kim B. Predictors of job satisfaction among police officers: Does personality matter? J Criminal
Justice. 2009;37:419-26, http://dx.doi.org/10.1016/j.jcrimjus. 2009.07.001.

18. Huang M, Wu Z, Tang G. How does personality relate to mental health in service industry setting? The mediating effects of emotional labor strategies. Sheng Li Hsueh Pao. 2010;42(12):1175-89, http://dx.doi.org/10.3724/SP.J. 1041.2010.01175.

19. Othman N, Ghazali Z, Ahmad S. Resilience and work engagement: A stitch to nursing care quality. J Global Manage. 2013;6(1):40-8.

20. Xanthopoulou D, Bakker A, Fischbach A. Work engagement among employees facing emotional demands. J Personnel Psychol. 2013;12(2):74-84, http://dx.doi.org/10.1027/18665888/a000085.

21. Bloch A. Emotion work, shame, and post-Soviet women entrepreneurs: Negotiating ideals of gender and labor in a global economy. Identities. 2011;18(4):317-51, http:// dx.doi.org/10.1080/1070289X.2011.654104.

22. Hoang KK. Economies of emotion, familiarity, fantasy, and desire: Emotional labor in Ho Chi Minh city's sex industry. Sexualities. 2010;13(2):255-72, http://dx.doi.org/ $10.1177 / 1363460709359224$.

23. Moran CM, Diefendorff JM, Greguras GJ. Understanding emotional display rules at work and outside of work: The effects of country and gender. Motiv Emotion. 2013;37:32334, http://dx.doi.org/10.1007/s11031-012-9301-x.

24. Klassen RM, Usher EL, Bong M. Teachers' collective efficacy, job satisfaction, and job stress in cross-cultural context. J Exp Educ. 2010;78:464-86, http://dx.doi. org/10.1080/00220970903292975.

25. Hu Q, Schaufeli WB, Hessen DJ, Salanova M, Taris TW, Hakanen J, et al. "East is East and West is West and never the twain shall meet:" Work engagement and workaholism across eastern and western cultures. J Behav Soc Sci. 2014;1:6-24.

26. Kwiatkowska A. [Cultural diversity and world economic development: Does the map of wealth and poverty coincide with the cultural map of the world?]. Zesz Nauk Wyz Szk Zarz Prawa. 2009;4(33):5-32. Polish. 
27. Hofstede G, Hofstede GJ, Minkov M. Cultures and organizations, software of the mind: Intercultural cooperation and its importance for survival. New York: McGraw Hill; 2010.

28. Hochschild AR. [The managed heart: The commercialization of human feeling]. Warszawa: Wydawnictwo Naukowe PWN; 2009. Polish.

29. Rafaeli A, Sutton RI. Expression of emotion as part of the work role. Acad Manage Rev. 1987;12(1):23-37.

30. Ashforth BE, Humphrey RH. Emotional labor in service roles: The influence of identity. Acad Manage Rev. 1993;18(1):88115, http://dx.doi.org/10.5465/AMR.1993.3997508.

31. Brotheridge CM, Grandey AA. Emotional labor and burnout: Comparing 2 perspectives of "people work". J Vocat Behav. 2002;60(1):17-39, http://dx.doi.org/10.1006/jvbe.2001.1815.

32. Brotheridge CM, Lee RT. Testing a conservation of resources model of the dynamics of emotional labor. J Occup Health Psychol. 2002;7(1):57-67, http://dx.doi.org/10.1037/10768998.7.1.57.

33. Szczygieł D, Bazińska R, Kadzikowska-Wrzosek R, Retowski S. [Emotional labor in service roles - Conceptualization, theories and research]. Psychol Spol. 2009;3(11):155-66. Polish.

34. Bazińska R, Kadzikowska-Wrzosek R, Retowski S, Szczygieł D. [Emotional labour strategies - Construction and construction validity of Emotional Labour Scale]. In: Zawadzka AM, editor. [Psychology of organizational management]. Warszawa: PWN; 2010. p. 170-95. Polish.

35. Wróbel M. [Emotional labor and burnout in teachers. The moderating role of emotional intelligence]. Psychol Spol. 2013;1(24):53-66. Polish.

36. Grandey AA. Emotional regulation in the workplace: A new way to conceptualize emotional labor. J Occup Health Psychol. 2000;5(1):95-110, http://dx.doi.org/10.1037/1076-8998.5.1.95.

37. Lee RT, Brotheridge CM. Words from the heart speak to the heart. A study of deep acting, faking, and hiding among child care workers. Career Dev Int. 2011;16:401-20, http://dx.doi. org/10.1108/13620431111158805.

38. Brotheridge CM, Lee RT. Development and validation of the Emotional Labour Scale. J Occup Organ Psychol.
2003;76(3):365-79, http://dx.doi.org/10.1348/096317903769 647229.

39. Montgomery AJ, Panagopolou E, de Wildt M, Meenks E. Work-family interference, emotional labor and burnout. J Manage Psychol. 2006;21(1):36-51, http://dx.doi. org $/ 10.1108 / 02683940610643206$.

40. Shulei M, Miner H. Emotional labor: Surface acting and deep acting, which one is better? Sheng Li Hsueh Pao. 2006:38(2):262-70.

41. Kim HJ. Hotel service providers' emotional labor: The antecedents and effects on burnout. Int J Hosp Manage. 2008; 27(2):151-61, http://dx.doi.org/10.1016/j.ijhm.2007.07.019.

42. Noor NM, Zainuddin M. Emotional labor and burnout among female teachers: Work-family conflict as mediator. Asian J Soc Psychol. 2011;14(4):283-93, http://dx.doi. org/10.1111/j.1467-839X.2011.01349.x.

43. Biron M, van Veldhoven M. Emotional labour in service work: Psychological flexibility and emotion regulation. Hum Relat. 2012;65(10):1259-82, http://dx.doi.org/ $10.1177 / 0018726712447832$.

44. Gopalan N, Culbertson SS, Leiva PI. Explaining emotional labor's relationships with emotional exhaustion and life satisfaction: Moderating role of perceived autonomy. Univ Psychol. 2013;12(2):347-56, http://dx.doi.org/10.11144/ Javeriana.UPSY12-2.eelr.

45. Allen JA, Diefendorff JM, Ma Y. Differences in emotional labor across cultures: A comparison of Chinese and U.S. service workers. J Bus Psychol. 2014;29(1):21-35, http://dx.doi. org/10.1007/s10869-013-9288-7.

46. Mikolajczak M, Menil C, Luminet O. Explaining the protective effect of trait emotional intelligence regarding occupational stress: Exploration of emotional labour processes. J Res Pers. 2007;41(5):1107-17, http://dx.doi.org/10.1016/ j.jrp.2007.01.003.

47. Karim J, Weisz R. Emotional intelligence as a moderator of affectivity/emotional labor and emotional labor/psychological distress relationships. Psychol Stud. 2011;56(4):348-59, http://dx.doi.org/10.1007/s12646-011-0107-9. 
48. Randolph KL, Dahling JJ. Interactive effects of proactive personality and display rules on emotional labor in organizations. J Appl Soc Psychol. 2013;43(12):2350-9, http://dx.doi. org/10.1111/jasp.12184.

49. Wróbel M. Can empathy lead to emotional exhaustion in teachers? The mediating role of emotional labor. Int J Occup Med Environ Health. 2013;26(4):581-92, http://dx.doi. org/10.2478/s13382-013-0123-1.

50. Austin EJ, Dore TCP, O'Donovan KM. Associations of personality and emotional intelligence with display rule perceptions and emotional labour. Pers Individ Dif. 2008;44(3): 679-88, http://dx.doi.org/10.1016/j.paid.2007.10.001.

51. Kiffin-Petersen SA, Jordan CL, Soutar GN. The big five, emotional exhaustion and citizenship behaviors in service settings: The mediating role of emotional labor. Pers Individ Dif. 2011;50(1):43-8, http://dx.doi.org/10.1016/ j.paid.2010.08.018.

52. Basim HN, Begenirbas M, Yalcin RC. Effects of teacher personalities on emotional exhaustion: Mediating role of emotional labor. Educ Sci Theory Pract. 2013;13(3):1488-96, http://dx.doi.org/10.12738/estp.2013.3.1509.

53. Buckner VJE, Mahoney KT. Individual differences and emotional labor: An experiment on positive display rules. Pers Individ Dif. 2012;53(3):251-6, http://dx.doi.org/10.1016/ j.paid.2012.03.028.

54. Sohn H, Lee TJ. Relationship between HEXACO personality factors and emotional labour of service providers in the tourism industry. Tour Manage. 2012;33(1):116-25, http:// dx.doi.org/10.1016/j.tourman.2011.02.010.

55. Schaufelli WB, Salanova M, Gonzalez-Roma V, Bakker AB. The measurement of engagement and burnout: A 2 sample confirmatory factor analytic approach. J Happiness Stud. 2002;3:71-92, http://dx.doi.org/10.1023/A:1015630930326.

56. Shimazu A, Miyanaka D, Schaufeli WB. Work engagement from a cultural perspective. In: Albrecht SA, editor. Handbook of employee engagement: Perspectives, issues, research and practice. Cheltenham: Edward Elgar Publishing; 2010. p. 364-72, http://dx.doi.org/10.4337/9781849806374.00040.
57. Kim HJ, Shin KH, Swanger N. Burnout and engagement: A comparative analysis using the Big Five personality dimensions. Int J Hosp Manag. 2009;28:96-104, http://dx.doi. org/10.1016/j.ijhm.2008.06.001.

58. Hobfoll S. Stress culture and community. New York: Plenum Press; 1998.

59. Liao F, Yang LQ, Wang M, Drown D, Shi J. Team-member exchange and work engagement: Does personality make a difference? J Bus Psychol. 2013;28:63-77, http://dx.doi. org/10.1007/s10869-012-9266-5.

60. Zaidi NR, Wajid RA, Zaidi FB, Zaidi GB, Zaidi MT. The big 5 personality traits and their relationship with work engagement among public sector university teachers of Lahore. Afr J Bus Manage. 2013;7(15):344-53, http://dx.doi. org/10.5897/AJBM12.290.

61. Woods SA, Sofat JA. Personality and engagement at work: The mediating role of psychological meaningfulnes. J Appl Psychol. 2013;43:2203-10, http://dx.doi.org/10.1111/ jasp.12171.

62. Zalewska A. [The satisfaction with job scale - A measure of cognitive aspect of overall job satisfaction]. Acta Univ Lodz Folia Psychol. 2003;7:49-61. Polish.

63. Jaros R, Zalewska A. [Reactivity and job satisfaction]. Acta Univ Lodz Folia Psychol. 2003;7:63-75. Polish.

64. Judge TA, Heller D, Mount M. Five-factor model of personality and job satisfaction: A meta-analysis. J Appl Psychol. 2002;87(3):530-41, http://dx.doi.org/10.1037//00219010.87.3.530.

65. Zawadzki B, Strelau J, Szczepaniak P, Śliwińska M. [CostaMcCrae NEO-FFI Inventory of Personality. Polish adaptation]. Warszawa: PTP; 1998. Polish.

66. Finogenow M, Wróbel M, Mróz J. [Deep Acting and Surface Acting Scale (DASAS) - Preliminary psychometric properties of the Polish version of the Emotional Labour Scale by Brotheridge and Lee]. Med Pr. 2015;66(3):359-71. Polish.

67. Lee RT, Brotherigde CM. Validation and extension of the emotional labour scale: Evidence from day-care workers. 
Fifth International Conference on Emotions and Worklife; 2006 Aug 10-12; Atlanta, USA. Atlanta 2006

68. Chirkowska-Smolak T. [Psychological model of work engagement]. Poznań: Wydawnictwo Naukowe UAM; 2012. Polish.

69. Gore WL, Pincus AL. Dependency and the five-factor model. In: Widiger TA, Costa PT, editors. Personality disorders and the five-factor model of personality. 3rd ed. Washington: American Psychological Association; 2013. p. 163-77, http:// dx.doi.org/10.1037/13939-011.

70. Grandey AA, Foo SC, Groth M, Goodwin RE. Free to be you and me: A climate of authenticity alleviates burnout from emotional labor. J Occup Health Psychol. 2012;17(1):1-14, http://dx.doi.org/10.1037/a0025102.

71. Poraj G. [Personality as a teacher's burnout predictor]. Med Pr. 2009;60(4):273-82. Polish.

72. Tabała K, Strecz P, Kocur J. [Personality traits, coping styles and burnout symptoms in nursing assistants]. Med Og Nauk Zdr. 2014;20(3):270-5. Polish.

73. Barrick MR, Mount MK. Yes, personality matters: Moving on to more important matters. Hum Perform. 2005;18(4):359-72.
74. Templer KJ. Five-factor model of personality and job satisfaction: The importance of agreeableness in a tight and collectivistic Asian society. Appl Psychol. 2012;61(1):114-29, http://dx.doi.org/10.1111/j.1464-0597.2011.00459.x.

75. Barrick MR, Mount MK, Judge TA. Personality and performance at the beginning of the new millennium: What do we know and where do we go next? Int J Select Assess. 2001;9(1-2):9-30, http://dx.doi.org/10.1111/1468-238 9.00160 .

76. Lipińska-Grobelny A, Głowacka K. [A job satisfaction and a person - Environment fit's degree]. Przegl Psychol. 2009;52(2):181-94. Polish.

77. Leiter MP, Maslach C. Areas of worklife: A structured approach to organizational predictors of job burnout. In: Perrewé P, Ganster DC, editors. Research in occupational stress and well being: 3. Emotional and physiological processes and positive intervention strategies. Oxford: JAI Press/Elsevier; 2004. p. 91-134.

78. Hegney D, Plank A, Parker V. Extrinsic and intrinsic work values: Their impact on job satisfaction in nursing. J Nurs Manage. 2006;14(4):271-81, http://dx.doi.org/10.1111/ j.1365-2934.2006.00618.x.

This work is available in Open Access model and licensed under a Creative Commons Attribution-NonCommercial 3.0 Poland License - http://creativecommons.org/ licenses/by-nc/3.0/pl/deed.en. 